\title{
Snake bite envenomation: experience at King Abdulaziz Medical City, Riyadh
}

\author{
H. Al-Durihim, ${ }^{7}$ M. Al-Hussaini, ${ }^{1}$ S. Bin Salih, ${ }^{1}$ I. Hassan, ${ }^{2}$ M. Harakati ${ }^{1}$ and A. Al Hajjaj ${ }^{2}$
}

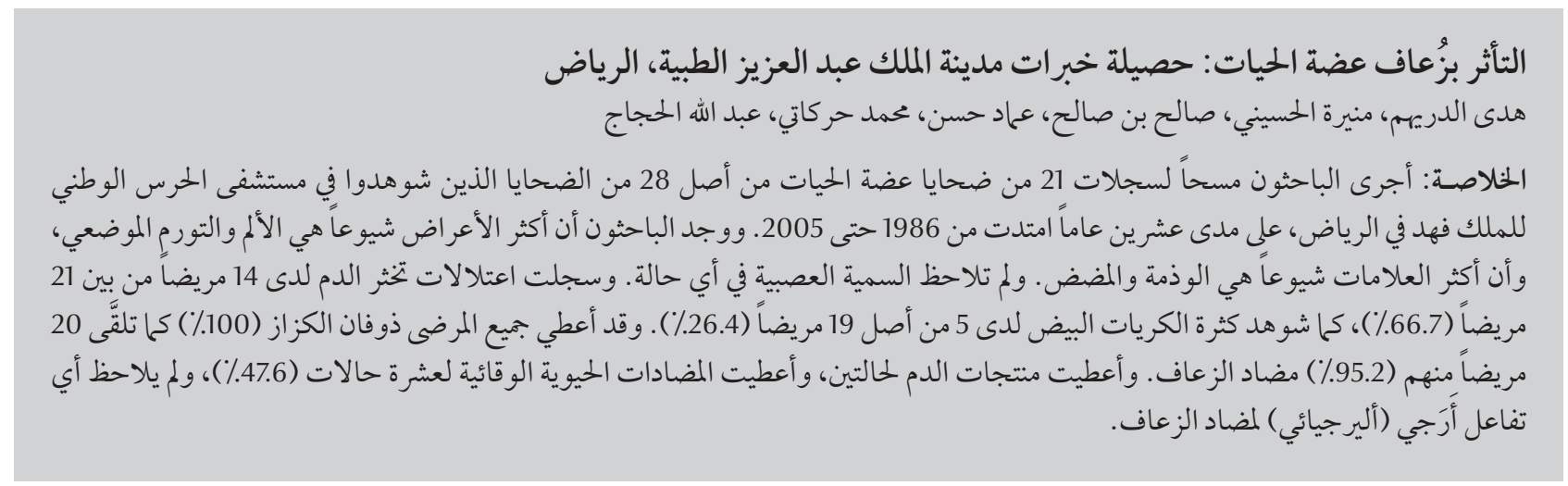

ABSTRACT We surveyed the records of 21 of the 28 snakebite victims seen at King Fahad National Guard Hospital in Riyadh over the 20-year period 1986-2005. The most common symptoms were local pain and swelling and the most common signs oedema and tenderness. Neurotoxicity was not noted in any case. Coagulopathy was recorded for $14 / 21$ patients $(66.7 \%)$ and 5/19 (26.4\%) had leukocytosis. All patients were given tetanus toxoid $(100 \%)$ and $20(95.2 \%)$ received antivenom. Blood products were administered in 2 cases and prophylactic antibiotics in 10 (47.6\%). No allergic reaction to antivenom was reported.

\section{Envenimation par morsure de serpent : une expérience réalisée à King Abdulaziz Medical City, à Riyad}

RÉSUMÉ Nous avons étudié les dossiers de 21 des 28 victimes de morsure de serpents prises en charge à I'hôpital King Fahad National Guard de Riyad (Arabie Saoudite) durant vingt ans, entre 1986 et 2005. Les symptômes les plus courants étaient une douleur et un gonflement au niveau de la morsure, et les signes les plus fréquents étaient un œdème et une sensibilité. Aucune neurotoxicité n'a été constatée. Une coagulopathie a été observée chez 14 des 21 patients (soit 66,7\% d'entre eux), et 5 malades sur 19 (26,4\%) ont développé une leucocytose. Tous les patients (100\%) ont reçu de l'anatoxine tétanique, et 20 (95,2\%) se sont vu donner du sérum antivenimeux. Des produits sanguins ont été administrés à deux patients, et une antibioprophylaxie à 10 d'entre eux (47,6\%). Aucune réaction allergique au sérum antivenimeux n'a été rapportée.

${ }^{7}$ Department of Medicine; ${ }^{2}$ Division of Internal Medicine, King Fahad National Guard Hospital, King Abdulaziz Medical City, Riyadh, Saudi Arabia (Correspondence to H.Al-Durihim: medicine1@ngha.med.sa).

Received 16/02/07; accepted 24/02/08 


\section{Introduction}

Annually, snake venom poisoning has 2.5 million victims and 100000 deaths worldwide. It is a complex medical emergency which may have a local effect on the bite site and may also result in damage to the major organ systems. There have been very few reports of snakebite from Saudi Arabia. This is probably because of under-reporting of actual cases as most victims may be desert dwellers with no access to medical care [1]. Excluding sea snake, there are at least 5 snakes in Saudi Arabia, which are capable of causing fatal bites: Arabian cobra (Naja haje arabica), which has neurotoxic effects leading to bulbar and respiratory paralysis; black desert cobra (Walterinnesia aegeptia), which causes local swelling; puff adder (Bitis arietans); stiletto snakes (Atractaspis microlepidoka andersoni and $A$. engaddensis), which can produce anaphylactic shock, coronary vasoconstriction and local necrosis; and saw scaled vipers (the most common snakes in Saudi Arabia) (Echis carinatus sochureki, Echis pyramidium and Echis coloratus), which cause severe homeostatic disturbance and local envenoming [1]. Death from snakebites usually results from haemorrhage complicating disseminated intravascular coagulation [2].

This report summarizes the characteristics of patients and complications and management of snakebites at King Abdulaziz Medical City, Riyadh from 1986 to 2005 and compares the results to other studies in Saudi Arabia.

\section{Methods}

This retrospective chart review was carried out at King Fahad National Guard Hospital, affiliated to King Abdulaziz Medical City, Riyadh, Saudi Arabia. The charts of all adult medical patients above the age of 12 years with a final diagnosis of snakebite as identified on the computer code during the period 1986-2005 were retrieved. Only cases with proper documentation of both clinical and laboratory evaluation and presenting to the emergency room (ER) within 25 hours of the snakebite were included in the study.

Diagnosis of snakebite was established by the ER physicians. Identification of type of snake was done by a specialist from the local snake poison centre only in cases where the implicated snake (caught or killed) was brought with the patient. The data were collected by physicians contributing in the study using a standard data sheet and included: age, sex and occupation of the victim; date and site of the bite; time elapsed before patient's arrival to the ER; symptoms and signs on presentation; laboratory results; complications and management provided including notes about interventions such as endotracheal intubation, haemodialysis, surgical debridement and fasciotomy.

The haematological parameters of the patients (complete blood count, prothrombin time, partial thromboblastin time, plasma fibrinogen, d-dimer) were checked using Coulter counter, spectrophotometers and laser methods as appropriate. Renal and liver functions were checked by automated bioanalyser method (Abbott Laboratories) according to the standard technique and/or the manufacturer's recommendations. Coagulopathy was defined as having one of the following: low platelets or fibrinogen levels, prolonged prothrombin time or partial thromboplastin time, high international normalized ratio (INR), elevated d-dimer or fibrin degradation products.

\section{Results}

During the study period, 28 adult snakebite victims were identified. On reviewing the charts, 7 were excluded: 3 patients spent the first few days in other hospitals, and the data were incomplete for the remaining 4 . The identification of the implicated snakes was only possible in 10 cases because even a description of the snake was not available in the rest of the cases: 7 were Cerastes cerastes, 1 Echis coloratus, 1 Bitis arietans and 1 American rattlesnake (this snake had been imported to the poison centre for venom extraction and the victim was a staff member who was bitten accidentally while holding the snake).

The male:female ratio was 9:1; mean age was 32 (standard deviation $12.7)$ years. The vast majority of incidents occurred in the spring (38\%) and summer $(33 \%)$ and outdoors in rural areas (95.2\%). The hands and feet, the most exposed parts of the body, were the most frequently bitten sites. Victims were mostly people living or working in rural areas. The commonest symptoms were pain and swelling (Table 1) and the commonest signs were oedema, tenderness and fang marks (Table 1). Coagulopathy was detected in $66.7 \%$ of the patients (Table 2). The time required for INR to normalize was 2-48 (mean 26.1) hours and the duration of hospitalization was 1-51 (mean 6.95) days. Taking longer to present to hospital was associated with more complications such as compartment syndrome and cerebral haemorrhage; $52.4 \%$ of the victims arrived at the ER in less than 1 hour.

Polyvalent antivenom (Pasteur anti-bitis-Echis-naja) was administered intravenously to 20 (95.2\%) patients in doses ranging from 2 to 5 vials.

Two patients were given fresh frozen plasma. All of the 21 patients received tetanus toxoid booster and 10 (47.6\%) were given prophylactic antibiotics.

\section{Complications}

Four patients (19\%) had compartment syndrome and needed fasciotomy and 1 required amputation of the bitten finger. 


\begin{tabular}{|c|c|c|}
\hline \multicolumn{3}{|c|}{$\begin{array}{l}\text { Table } 1 \text { Common symptoms and } \\
\text { local and systemic signs in victims } \\
\text { of snakebite envenomation }(n=21) \\
\text { admitted to King Fahd National Guard } \\
\text { Hospital, 1986-2005 }\end{array}$} \\
\hline Variable & No. & $\%$ \\
\hline \multicolumn{3}{|l|}{ Symptom } \\
\hline Pain & 21 & 100 \\
\hline Swelling & 21 & 100 \\
\hline Dizziness & 5 & 24 \\
\hline Numbness & 4 & 19 \\
\hline Dyspnoea & 2 & 10 \\
\hline Vomiting & 2 & 10 \\
\hline \multicolumn{3}{|l|}{ Sign } \\
\hline Oedema & 21 & 100 \\
\hline Tenderness & 21 & 100 \\
\hline Fang marks & 17 & 81 \\
\hline Tachycardia & 10 & 48 \\
\hline Tachypnoea & 6 & 29 \\
\hline Ecchymosis & 3 & 14 \\
\hline Hypotension & $1^{\mathrm{a}}$ & 5 \\
\hline Fever & 1 & 5 \\
\hline Bullae & 1 & 5 \\
\hline Vegetative state & 1 & 5 \\
\hline
\end{tabular}

${ }^{a} 70 / 40 \mathrm{~mm} \mathrm{Hg}$.

Renal involvement in the form of haematuria, proteinuria and rhabdomyolysis was seen in 4 (19\%) cases (Table 2).

One (4.8\%) mortality was recorded. The victim was a 75 -year-old previously healthy Bedouin man, who presented to the hospital ER in a vegetative state
18 hours after the snakebite. The patient was initially diagnosed as having acute inferior wall myocardial infarction, rhabdomyolysis requiring haemodialysis, disseminated intravascular coagulation and haemorrhagic cerebral infarction. The patient was intubated because of deteriorating Glasgow coma scale to $3 / 15$. His clinical course was complicated by sepsis that led to death after 51 days in the intensive care unit.

\section{Discussion}

Systemic toxicity of snake venom differs according to the type of snake, age and size of the victim, and time elapsed before treatment. Main symptoms of pain and swelling in all $(100 \%)$ patients in our series compares to $80.5 \%$ and $77 \%$ respectively reported from Al-Baha [3] and King Khalid University Hospital in Riyadh [4], although those studies were carried out over a shorter period, 7 years and 6 years respectively. Thrombocytopenia occurred in $19 \%$ of cases in our series compared with $53 \%$ of cases in the report from Al-Baha [3]. None of the patients in our study developed neurological complications while $1 \mathrm{pa}-$ tient in Al-Baha had bulbar palsy which developed 6 hours after the bite.

Coagulopathy was the most common complication observed in our

\begin{tabular}{|c|c|c|c|}
\hline \multicolumn{4}{|c|}{$\begin{array}{l}\text { Table } 3 \text { Comparison of complications and laboratory derangements with other } \\
\text { studies from Saudi Arabia }\end{array}$} \\
\hline Condition & $\begin{array}{c}\text { Riyadh } \\
\text { (this study) } \\
\text { (21 cases, } \\
\text { 1986-2005) }\end{array}$ & $\begin{array}{c}\text { Al-Baha [3] } \\
\text { (82 cases, } \\
\text { 1983-1989) }\end{array}$ & $\begin{array}{c}\text { Riyadh [4] } \\
(21 \text { cases, 1985- } \\
\text { 1990) }\end{array}$ \\
\hline Coagulopathy & $66.7 \%$ & $44.0 \%$ & $31.9 \%$ \\
\hline Leukocytosis & $26.3 \%(5)^{\mathrm{a}}$ & $56.1 \%(46)$ & $42.9 \%(9)$ \\
\hline Local complications & $19.0 \%^{\mathrm{b}}$ & $9.8 \%^{c}$ & $11.2 \%^{\mathrm{d}}$ \\
\hline Renal impairment & $19.0 \%(4)$ & Not reported & $4.5 \%(1)$ \\
\hline Mortality & $4.8 \%(1)$ & $1.2 \%(1)$ & 0 \\
\hline Neurotoxicity & 0 & 1 & 0 \\
\hline Anti-venom adverse effects & 0 & 1 (lethargy) & 1 \\
\hline
\end{tabular}

${ }^{a}$ 5/19 for whom WBC count was available

${ }^{\circ} 4$ compartment syndrome.

5 local necrosis requiring grafting; 3 compartment syndrome requiring fasciotomy.

${ }^{d} 3$ ulceration and delayed wound healing. study. However in 2 other studies in Saudi Arabia, at King Fahad Hospital , Al-Baha [3] and King Khalid University Hospital, Riyadh [4] leucocytosis was the most commonly observed complication (Table 3).

Most of the reports of snakebite do not mention the identification of the implicated snakes. This is not surprising considering the nocturnal habits of snakes and the fact that most of the bites occur at night when it is impossible for the victim or to catch or kill the snake for the purpose of identification. In our series, the implicated snake was identified in $48 \%$ cases, with the most common being the horned viper, Cerastes cerastes ( $70 \%$ of the identified snakes). This compares to identification of the implicated snake in $11 \%$ of snakebite cases in a report from Asir region of Saudi Arabia [5] where Echis coloratus was the commonest identified snake (67\% of the cases). This higher rate of snake identification at our centre could be due to the fact that most of the patients presenting were males belonging to Saudi National Guard or their dependents, who are advised about how to avoid and tackle snakes as a part of training.

The commonest identified snake in our series, Cerastes cerastes, has a haemotoxic venom and is considered to be the most distinctive and abundant snake in the great deserts of North Africa and the Middle East. Many studies have been published on Cerastes cerastes venom and more than 13 different toxins have been identified [6]. These include serine proteases and other thrombin-like enzymes (fibrinogenases) which are likely to be responsible for causing hypofibrinogenaemia in humans; activation of platelet aggregation; agglutination, which can cause thrombocytopenia; and inhibition of platelet aggregation, which could contribute to a tendency to bleeding [7].

Renal impairment was seen in 4 of our cases. Acute renal failure following bites by various snakes has been associated with glomerular, tubular, interstitial 
and vascular lesions and occasionally with cortical necrosis [7-9]. Hypotension and shock in 1 of our patients could have been due to hypovolaemia and myocardial dysfunction. Only 52.4\% of our patients reached the hospital in less than 1 hour, which suggests the need for better health education. One patient died due to delay in presentation to the hospital, with resultant acute renal failure, myocardial infarction and haemorrhagic cerebral infarction. However, local effects such as compartment syndrome, necrosis and coagulopathy were not related to the time needed for antivenom to be injected as some patients with these complications arrived at the hospital in less than 1 hour. It is important that the snakebite victim is transported to health care facility as soon as possible even if there are no signs of toxicity since these may not develop immediately $[10]$. All patients should be observed for 6-12 hours [11].
About half the cases in this study were given antibiotics: some authors recommend the use of prophylactic antibiotics, the practice is, however, controversial as some reports suggest that it may not decrease wound infection rates or improve outcome, so routine prophylactic antibiotics may not be warranted [12-14]. There is need for prospective studies on the effects of use of prophylactic antibiotics to prevent infection following snakebite.

Our study was limited by being based on retrospective review of documented symptoms and signs, a methodology with inherent weaknesses. There is no standard method used for the management of snake bite victims in our centres. Data insufficiency as a result of incomplete records was encountered in a number of cases. Larger prospective studies based on a standard protocol are needed.
In conclusion, having the antivenom available in family health care centres (normally these are nearer to the location of the incident than hospitals) and educating rural men about the hazards and treatment of snakebites and the importance of rapid transfer to a medical centre may help to decrease morbidity resulting from snake bite in the region.

\section{Acknowledgement}

We would like to express our sincere thanks to the colleagues and medical staff who gave their support and contribution to this study with specialmention to D. Mohammad Yousuf, who gave an extra effort to edit the study. Our appreciation also goes to Dr Osaima Khair, who made the translation from English to Arabic and to all our colleagues for their support and suggestions.

\section{References}

1. Warrell DA. Venomous bites and stings in Saudi Arabia. Saudi medical journal, 1993, 14:196-202.

2. Tillbury CR et al. Acute renal failure following the bite of Burton's carpet viper, Echis coloratus Gunther, in Saudi Arabia: case report and review. Saudi medical journal, 1987, 8:87-95.

3. Al-Mohareb F, Al-Sadoon M. Outcome of snake bite in AlBaha. Annals of Saudi medicine, 1994, 14:26-9.

4. Fahad M, Mohamed H. Clinico-hematological characteristics of snakebites in inland Saudi Arabia. Bahrain medical bulletin, 1992, 14:82-5.

5. Malik GM. Snake bites in adults from the Asir region of southern Saudi Arabia. American journal of tropical medicine \& hygiene, 1995, 52:314-7.

6. Theakston RDG, Kamiguti AS. A list of animal toxins and some other natural products with biological activity. Toxicon, 2002, 40:579-651.

7. Schneemann $\mathrm{M}$ et al. Life-threatening envenoming by the Saharan horned viper (Cerastes cerastes) causing micro-angiopathic haemolysis, coagulopathy and acute renal failure: clinical cases and review. Quarterly journal of medicine, 2004, 97:717-27.

8. Sant SM, Purandare NM. Autopsy study of the cases of snakebite with special reference to renal lesions. Journal of postgraduate medicine, 1972, 18:181-8.

9. Oram $\mathrm{S}$ et al. Renal cortical calcification after snakebite. British medical journal, 1963, 1:1647-8.

10. Khrishel S. Venomous snakebites in United States. Emergency medicine clinics of North America, 1997, 15:473-6.

11. Chang CG et al. Pit viper envenomation in pregnancy. Case report and literature review. Journal of emergency medicine, 2006, 30:167-9.

12. Clark RF. Venomous snake bite. In: Rakel RE, ed. Conn's current therapy. Philadelphia, WB Saunders, 1995:1080-2.

13. Clark RF, Selden BS, Furbee B. The incidence of wound infection following Crotalid envenomation. Journal of emergency medicine, 1993, 11:583-6.

14. Weed HG. Nonvenomous snakebite in Massachusetts: prophylactic antibiotics are unnecessary. Annals of emergency medicine, 1993, 22:220-4. 